\title{
Tendon transfer for irreparable rotator cuff tears: indications and surgical rationale
}

\author{
Giovanni Merolla ${ }^{1,2}$ \\ Claudio Chillemi ${ }^{3}$ \\ Vincenzo Franceschini ${ }^{4}$ \\ Simone Cerciello ${ }^{1}$ \\ Giorgio Ippolito 4 \\ Paolo Paladini ${ }^{1}$ \\ Giuseppe Porcellini ${ }^{1}$
}

1 Unit of Shoulder and Elbow Surgery, D. Cervesi Hospital, Cattolica - AUSI della Romagna Ambito Territoriale di Rimini, Italy

2 Biomechanics laboratory "Marco Simoncelli", D. Cervesi Hospital, Cattolica - AUSI della Romagna Ambito Territoriale di Rimini, Cattolica, Italy

3 Department of Orthopedics and Traumatology, Istituto Chirurgico Ortopedico Traumatologico (ICOT), Latina, Italy

4 Department of Orthopedics and Traumatology, Sapienza University of Rome, Rome, Italy

\section{Corresponding author:}

Giovanni Merolla

Unit of Shoulder and Elbow Surgery and

Biomechanics laboratory "Marco Simoncelli"

AUSI della Romagna Ambito Territoriale di Rimini

Via L. V. Beethoven 1

47822 Cattolica, Italy

E-mail: giovannimerolla@hotmail.com; giovanni.merolla@ausern.net

\section{Summary}

Background: treatment of symptomatic irreparable rotator cuff tears is extremely challenging because, at present, there are no ideal solutions to this problem. Many patients respond favorably to nonsurgical treatment. However, when conservative measures fail to improve the patient's pain and disability, surgery should be considered. Methods: different surgical techniques are available and the choice of the most appropriate procedure depends on the presenting symptoms, age of the patient, functional demand, medical comorbidities, joint stability and presence of arthritic changes. The transposition of the surrounding muscles to replace the rotator cuff function represents a viable option in the treatment of younger patients without glenohumeral osteoarthritis and with severe functional limitation. Purpose: aim of this study is to give an overview of the currently available evidence regarding tendon transfer procedures for irreparable rotator cuff tears.

KEY WORDS: shoulder, rotator cuff, irreparable tears, tendon transfer.

\section{Introduction}

Rotator cuff tears (RCT) represent one of the most common cause of pain and disability of the shoulder. Epidemiological studies have shown that RCT occur more frequently after a certain age, with a prevalence ranging from 30 to $50 \%$ in patients older than 50 years $^{1}$, and that, in most of cases, they are progressive ${ }^{2}$. Although the pathogenesis of $\mathrm{RCT}$ remains unclear, two main theories have been developed: the extrinsic theory and the intrinsic one ${ }^{3}$. In 1972 Neer $^{4}$ developed the concept that RCT resulted from the extrinsic mechanical compression caused by a hooked acromion (subacromial impingement). However, recent evidence strongly suggests that most of RCT are caused by primary intrinsic degeneration of the rotator cuff ${ }^{5}$ which result from the combination of the natural process of aging, poor vascularity, altered biology and inferior mechanical properties $^{6-8}$. In addition, a genetic component for the development of RCT has also been identified and theorized to be related to polymorphism of collagen genes $^{9}$. Basing on these findings, some studies have suggested that RCT do not heal spontaneously and that they tend to grow larger over time ${ }^{1,10,11}$. The treatment of choice in symptomatic "cases" is the direct reattachment of the torn tendon to the foot-print through either open or arthroscopic surgery. However, some tears can progress to the point of becoming irreparable. Several classification systems have been developed to describe RCT based on different parameters ${ }^{12-18}$ (Tab. 1). The term irreparable is often incorrectly used and ably interchanged with with the term massive but not all massive tears ${ }^{10}$ (Fig. 1). It is possible to define irreparable tears as those that, because of their size and retraction, cannot be repaired primarily to their insertion on the tuberosities despite conventional techniques of mobilization and soft-tissue releases ${ }^{19,20}$. Moreover, irreparable $\mathrm{RCT}$ typically present with atrophy and fatty degeneration of the respective muscles that lead to impaired muscle quality and thus to defective contrac- 
Table 1. System of classification for rotator cuff tears.

\begin{tabular}{|c|c|c|}
\hline Authors & Criteria & Method of assessment \\
\hline DeOrio \& Cofield 28 & Size & Open surgery \\
\hline Snyder ${ }^{31}$ & Size, retraction & Arthroscopy \\
\hline Patte $^{32}$ & Location, size, retraction, muscle quality, state of the LHB & MRI \\
\hline Ellmann \& Gartsman 30 & Morphology & Arthroscopy \\
\hline Lafosse $^{36}$ & Isolated subscapularis tear & Arthroscopy \\
\hline Goutallier ${ }^{33}$ & Muscle fatty degeneration & CT scan \\
\hline Fuchs ${ }^{34}$ & Muscle fatty degeneration & MRI \\
\hline
\end{tabular}

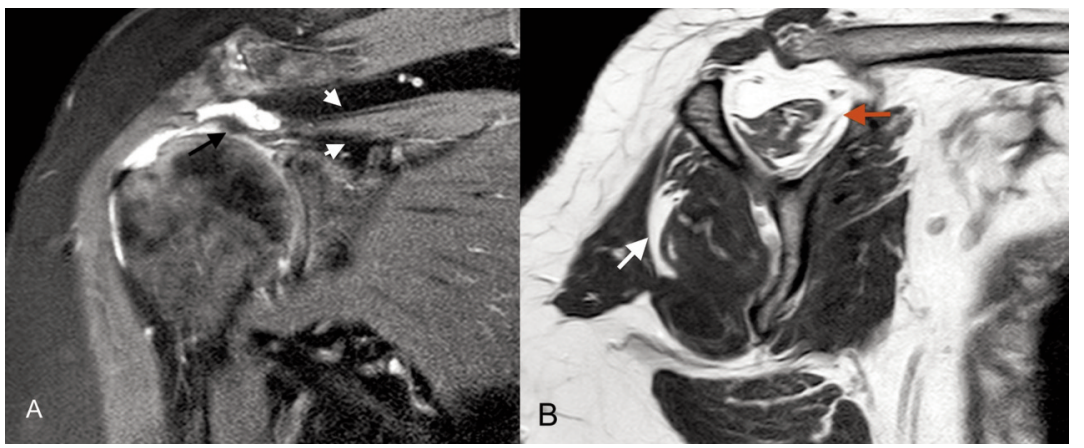

Figure 1. Magnetic Resonance (MR) of the right shoulder of a 68-year-old woman. A) Paracoronal view shows a massive supraspinatus tear. The tendon is retracted more than $5 \mathrm{~cm}$ (black arrow) and the volume of muscle belly in the supraspinatus fossa is reduced (white head arrows). B) Parasagittal view demonstrates fatty infiltration grade II of the supraspinatus muscle (red arrow) and grade I of the infraspinatus (white arrow). tion even if direct repairs are structurally success$\mathrm{ful}^{2,21}$. Obviously in presence of an irreparable RCT, also the shoulder biomechanics is altered. In the normal shoulder, the deltoid and rotator cuff muscles work synergistically to maintain a balanced force couple around the joint in both the coronal and the transverse plane, with coactivation of agonist and antagonist muscles, as well as coordinated activation of the agonist and inhibition of the antagonist mus$\mathrm{cle}^{22,23}$. In particular, the deltoid and rotator cuff inferior to the humeral head equator maintain a balanced coronal force couple, while the subscapularis and infraspinatus/teres minor complex balance each other in the transverse plane 23,24 . In this way, the rotator cuff acts as a dynamic stabilizer, resisting upward motion of the humeral head during contraction of the deltoid muscle $20,23,25$. When there is an irreparable RCT, the stabilizing force couple is lost, allowing the humeral head to displace superiorly for the contraction of deltoid. This is associated with a loss of elevation and, in some cases, with superior shoulder instability ${ }^{20}$. For this reason, acromiohumeral distance (evaluated on X-ray) represents another parameter that may be used to assess if a RCT is reparable ${ }^{10}$, with some studies suggesting that an acromiohumeral distance of $<7 \mathrm{~mm}$ is associated with decreased likelihood of reparability ${ }^{26}$. Patients with irreparable RCT can present a variety of clinical manifestations. They may have no symptoms or mild symptoms, or they may be completely disabled and have severe pain ${ }^{20}$. Pain is the most frequent symptom, particularly at night and during activities of daily living, and it is often combined with functional impairment ${ }^{20}$. The management of symptomatic irreparable RCT is still controversial and often the results are less favorable and predictable. Many patients with irreparable RCT respond favorably to nonsurgical treatment ${ }^{27}$. When conservative measures fail to improve the patient's pain and disability, surgery should be considered. Surgical options include arthroscopic débridement with or without partial rotator cuff repair ${ }^{28}$, the use of rotator cuff allografts and synthetic grafts ${ }^{29}$, arthroplasty $^{30}$ and tendon transfer $2,10,31-33$. Among these techniques, the transposition of the surrounding muscles to replace the rotator cuff function represents a viable option. Aim of this study is to give an overview of the currently available evidence regarding tendon transfer for irreparable RCT.

\section{Tendon transfer procedures: rationale}

The choice of the most appropriate procedure depends on the presenting symptoms (pain and/or disability), age of the patient, functional demand, medical comorbidities, joint stability and presence of arthritic changes. The ideal candidate for a tendon transfer procedure is a young, active patient who does not have glenohumeral osteoarthritis but has severe disability related to weakness and loss of external rotation $20,24,32,33$. The selection of the donor muscle-tendon unit is based on the structural deficit and impaired function. Although different muscle-tendon units have been proposed in the last decades (the long head of the triceps, the deltoid, the trapezius, the subscapularis, the latissimusdor$\mathrm{si}$, the pectoralis major, the pectoralis minor and the teresmajor) ${ }^{10,31}$, the most commonly used include the latissimus dorsi (LD) for posterosuperior RCT and the pectoralis major (PMa) for irreparable anterosuperior tears ${ }^{34,35}$. Aim of tendon transfer is to restore the force couples of the shoulder. With LD transfer the aim is to exert an external rotation force that allows for a more balanced state in the 
glenohumeral joint and thus replacing the function of the posterior force couple ${ }^{10}$. Aim of PMa transfer is to exert an internal rotation centering force there by replacing the function of the subscapularis. This is intended to function as the anterior force couple $^{10}$. Theoretically, restoration of the anterior and posterior force couples will allow the glenohumeral joint to pivot around a stable fulcrum. However, the critical function of the rotator cuff can never be fully replaced, and this balance in the force couple is rarely attained. The probable reason that the periscapular muscles cannot fully restore the normal function of the rotator cuff is their anatomic position and the resulting force vectors in relation to the anatomic positions of the native rotator cuff muscles ${ }^{10}$. In particular, in both subcoracoid and supracoracoid transfers the PMa transfer is always anterior to the normal position of the subscapularis. Moreover, the LD transfer is always inferior and posterior to the infraspinatus and teres minor muscles. This results in the development of a non-physiologic vector across the glenohumeral joint, leading to abnormal kinematics ${ }^{10}$.

\section{Tendon transfer procedures: techniques}

\section{Latissimus dorsi transfer}

The LD muscle is a large muscle, located along the dorso-lateral side of the trunk. The muscle has four points of origin, the spinous processes of the thoracic vertebrae (T7-T12), the inferior angle of the scapula, the iliac crest and the $9^{\text {th }}$ to $12^{\text {th }}$ ribs, and inserts to the medial edge of the bicipital groove of the humerus ${ }^{36}$. LD transfer provides a large, vascu- larized tendon that closes the cuff defect and exerts an external rotational moment, allowing more effective action of the deltoid muscle ${ }^{33}$. In its native location, the LD muscle contributes to internal rotation, retroversion, and abduction of the shoulder joint ${ }^{33}$. The procedure is performed on the patient in general anesthesia in the lateral decubitus position and includes a superior approach and an axillary approach. The superior approach is performed with a 5-cm supero-lateral skin incision made immediately lateral to the acromioclavicular joint going through the rafe between the anterior and the lateral deltoid without detaching it from the acromion. The rotator cuff is exposed to ascertain that the rupture is irreparable and trying an extensive mobilization of the retracted musculotendinous units to attempt a direct repair of the residual tendon bands. Then, the axillary approach is performed through a 12 to $15-\mathrm{cm}$ posterior skin incision that follow the lateral border of the LD, the muscle is identified and is released from the humeral shaft taking care to identify and separate the LD belly from teres major ${ }^{37,38}$ (Fig. 2 A, B). After exploration of the neurovascular bundle, the LD is mobilized and is pulled through the plane between the infraspinatus-teres minor (TMi) and the deltoid muscle (Fig. 3 A, B). The transferred tendon is anchored to the greater tuberosity in the area of supraspinatus tendon insertion with the use of 2 double-loaded suture anchors (Threvo FT; ConMed, Largo, FL, USA) (Fig. 4) or with transosseous sutures/bone trough. Alternatively, a small osteotomy can be performed to enhance tendon healing. Any part of the torn rotator cuff are then sutured to the medial edge of the LD tendon ${ }^{10}$. A post-operative period of 4-6 weeks of immobilization with the arm in
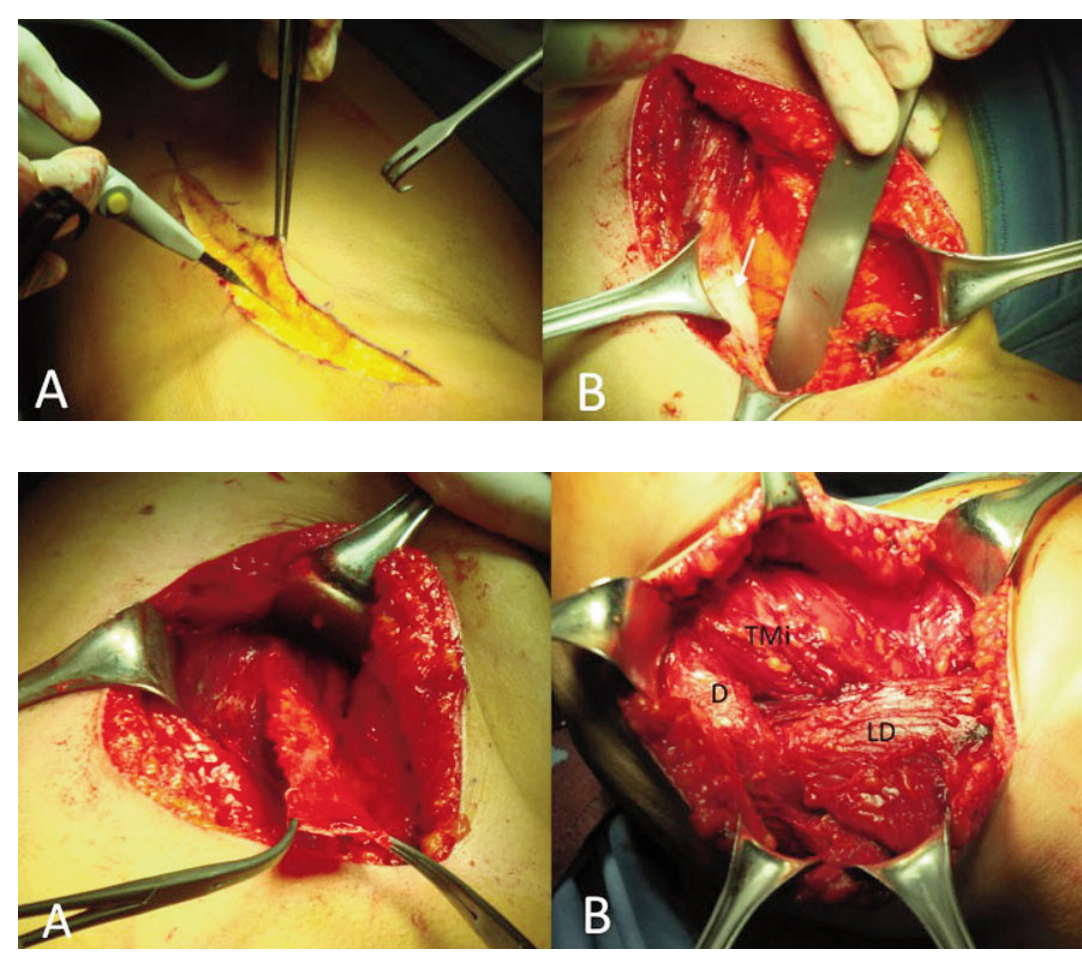

Figure 2 A, B. Axillary approach for latissimus dorsi (LD) transfer. A) The skin incision run along the lateral border of the LD; B) the muscle is identified and the tendon is released from the humeral shaft taking care to identify and separate the LD belly (white arrow) from teres major (TM) that is laterally retracted.

Figure 3 A, B. A) LD tendon is mobilized (white arrow) and pulled with its muscle belly; B) LD passed through the plane between the infraspinatus-teres minor and the deltoid muscle.D: deltoid; LD: latissimus dorsi; TMi: teres minor. 


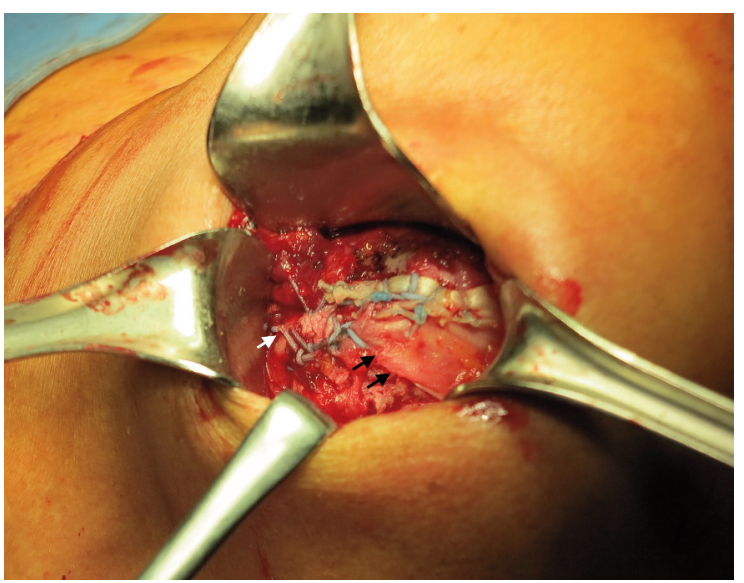

Figure 4. The transferred LD tendon (black arrows) is fixed to the greater tuberosity in the area of supraspinatus tendon insertion with suture anchors. Additional sutures are passed between the subscapularis (white arrow) and LD tendons to promote anterior stability and humeral head depression.

slight abduction and externally rotated is required $^{10,35,36,39}$. Gentle passive range of motion in abduction can begin immediately, but internal rotation and adduction are restricted until 6 weeks after surgery. At 6 weeks the brace may be removed and active range of motion is started. Strengthening exercises can be started in the third month ${ }^{10,35,36,39}$. When the LD tendon is transferred to the greater tuberosity, the muscle's internal rotator torque is removed and the function of the muscle changes into an external rotator ${ }^{36}$. This external rotation is accomplished by either a synergistically active tendon transfer or a tenodesis effect: electromyographic studies have suggested that in some cases the transfer is truly active whereas in others the patient cannot actively synchronize LD muscle activity with supraspinatus and infraspinatus muscle activity 39,40 . In both cases, the improved balance between the anterior and posterior soft tissue structures of the shoulder is believed to be biomechanically important to serve as a balanced fulcrum ${ }^{33}$. For this reason the subscapularis tendon and deltoid muscle origin must be intact in order to establish balanced force couples in the glenohumeral joint. Moreover, after transposition of the LD tendon, the muscle acts as a depressor of the shoulder. Depression of the humeral head, allows the deltoid muscle to contribute to the abduction and anteflexion of the shoulder more effectively 35,39 . LD tendon transfers were firstly used in patients with brachial plexopathies in order to treat the lack of external rotation ${ }^{10}$. This concept of using muscle transfer to improve shoulder external rotation was applied by Gerber et al. ${ }^{37}$ in the management of irreparable posterosuperior RCT.

In the majority of patients LD tendon transfer is very effective in reducing pain. However, the functional outcome is more variable $35,39,41,42$. Proper patient selection is critical. Factors associated with poor outcome include muscle dysfuction (subscapularis, deltoid, teres minor) and osteoarthritis of the gleno- humeral joint. In particular, Miniaci and MacLeod ${ }^{41}$ reported that fourteen out of seventeen patients who were treated with this transfer after a failed rotator cuff repair had a satisfactory result. Warner and Parsons ${ }^{42}$ reported a $73 \%$ overall patient satisfaction rate in a series of twenty-two patients treated with LD tendon transfer but a $27 \%$ re-rupture rate and significantly worse outcomes in patients who had a salvage procedure after a failed rotator cuff repair as opposed to a primary procedure. Iannotti et al. ${ }^{39}$ reported a $64 \%$ rate of satisfactory results in a series of fourteen patients and noted that female sex, poor preoperative shoulder function, and generalized muscular weakness were associated with an inferior clinical outcome. Gerber et al. ${ }^{35}$ reported after 10 years of follow-up an increase in the mean Subjective Shoulder Value from $29 \%$ preoperatively to $70 \%$, an increase of the mean Constant score from 56 to $80 \%$ and an improvement of pain score from 7 to 13 points. Mean flexion increased from $118^{\circ}$ to $132^{\circ}$, abduction from $112^{\circ}$ to $123^{\circ}$, and external rotation from $18^{\circ}$ to $33^{\circ}$. Poor results occurred in shoulders with insufficiency of the subscapularis muscle and fatty infiltration of the teres minor muscle.

\section{L’Episcopo procedure}

The procedure described by L'Episcopo in $1936^{43}$ had the scope to restore external rotation in patients with obstetrical plexus paralysis. A modified L'Episcopo technique has been proposed in 2002 by Hebermeyer et al. ${ }^{44}$ with the indication to restore loss of external rotation in patients with massive posterosuperior RCT. Operation is performed with the patient under general anesthesia in lateral decubitus using an axillary approach from the posterior border of the deltoid muscle to the axillary fold ${ }^{45}$. The deltoid muscle is elevated to expose the plane between the long head of the triceps and teres major muscle, and to identify the axillary nerve in the quadrangular space that is delimited by the humerus (laterally), long head of the triceps (medially), subscapularis (on the top), teres major and LD (down). The combined insertions of the LD and teres major tendons are dissected from the humerus taking care not to injure the radial nerve. The two tendons are reattached with Mason-Allen sutures on the lateral proximal humeral shaft - approximately $180^{\circ}$ lateral to the anatomical insertion - using a bone through or bone tunnels, as originally described by L'Episcopo or alternatively with suture anchors ${ }^{46}$. Although the LD transfer is the preferred surgical approach in patients with massive and irreparable RCT, good restore of shoulder function have been described with L'Episcopo technique, even if the grade of cuff arthropathy progress significantly at final follow-up 47 . An additional technique has been reported with satisfactory clinical outcomes for shoulder function by other authors who used only the teres major for infraspinatus muscle in irreparable $\mathrm{RCT}^{48}$. 


\section{Pectoralis major transfer}

PMa originates from the anterior surfaces of the medial clavicle, the length of the sternum, the cartilage of ribs 2 through 7 , and the aponeurosis of the external oblique muscle and inserts lateral to the bicipital groove. Its insertion consists of two distinct layers. The anterior lamina is the terminal portion of the clavicular head, while the posterior lamina originates from the sternal head. A variable third layer, the abdominal lamina, is derived from the aponeurosis of the external oblique muscle ${ }^{32}$. PMa contributes to flex, internally rotate, and adduct the humerus. Its transfer is indicated for patients with irreparable antero-superior cuff tear with minimal glenohumeral joint arthritic changes and a functioning deltoid muscle. The procedure is performed with the patient under general anesthesia in beach-chair position through a standard deltopectoral approach ${ }^{32}$. The deltoid is retracted laterally with the cephalic vein. Subdeltoid, subacromial, and subcoracoid adhesions are bluntly released. A biceps tenodesis or tenotomy is generally undertaken. The lesser tuberosity is exposed and an attemptis made to identify and mobilize the torn subscapularis tendon. If the subscapularis is deemed irreparable, a PMa transfer is performed. The lateral border of the conjoined tendon is identified and the entire conjoined tendon is dissected. The space between the pectoralis minor (PMi) and the conjoined tendon is entered by blunt dissection with the index fingers. The musculocutaneous nerve and its entrance into the muscle are identified. Thus, the space for the transferred muscle between the nerve and the conjoined tendon can be assessed $^{49}$. The superior insertion of the PMa on the humerus is identified lateral to the intertubercular sulcus $^{32}$. Three courses can be taken by the transferred tendon. It can be passed in the plane of its normal course but merely in a more superior direction and can then be attached to the lesser tuberosity of the humerus ${ }^{32,50}$. Conversely, the sternal lamina may be passed deep to the clavicular tendon but superficial to the conjoined tendon ${ }^{32,51}$. Lastly, the tendon (complete or partial) can be routed deep, through the interval between the conjoined tendon (superficial) and the musculocutaneous nerve ${ }^{32,49}$. In this way, a transfer is used to rebalance the forces on the humeral head through an inferiorly directed force vector. If rerouted deep to the conjoined tendon, the PMa transfer is thought to also reduce subcoracoid impingement through a soft-tissue interposition effect that aids in pain relief ${ }^{32}$. Care should be taken not to mobilise more than $8 \mathrm{~cm}$ from the lateral border of the muscle in order to protect the lateral pectoral nerve 49 . The tendon is then transferred to the upper lesser tuberosity or the anterior aspect of the greater tuberosity depending on the length and excursion of the tendon (Fig. $5 \mathrm{~A}$ ). The site of attachment is burred, providing a surface of punctate bleeding bone. The tendon is then secured to the tuberosity by use of transosseous sutures or bone anchors $^{32}$. Postoperatively, the shoulder is immobilized for 4-6 weeks in a rigid orthosis $32,34,49-51$. Passive range of motion can be started after 4 weeks but it is restricted within a safe range determined intraoperatively in order to protect the transfer. Active range of motion is allowed after 6 weeks and strengthening exercise after 2 months. However, internal rotation against resistance is allowed only 3 months after surgery32,34,49-51. The sub-conjoined tendon transfer has the theoretic advantage of producing a force vector that better simulates that of the native subscapularis tendon (Fig. 5 B). A second advantage of the subcoracoid transfer is that the transferred tendon produces a static soft-tissue interposition between the humerus and the coracoid process, minimizing anterior humeral translation and decreasing the risk of coraco-humeral impingement ${ }^{32}$. One potential disadvantage of the subcoracoid technique is that surgical dissection, as well as the increased bulk of the transferred musculotendinous unit, risks injury to the musculocutaneous nerve and brachial plexus. For this reason, split-tendon transfers are also frequently performed $^{52}$. If a partial transfer of the PMa is chosen, the two laminae are bluntly separated for selective transfer. This is achieved by retracting the clavicular head proximally and initiating the separation at the level of the musculotendinous junction ${ }^{32}$. Despite overlapping insertions, either the anterior or posterior lamina can be elevated while leaving the other one intact on the humerus ${ }^{32}$. Different studies reported outcomes after PMa transfer for irreparable anterosu-

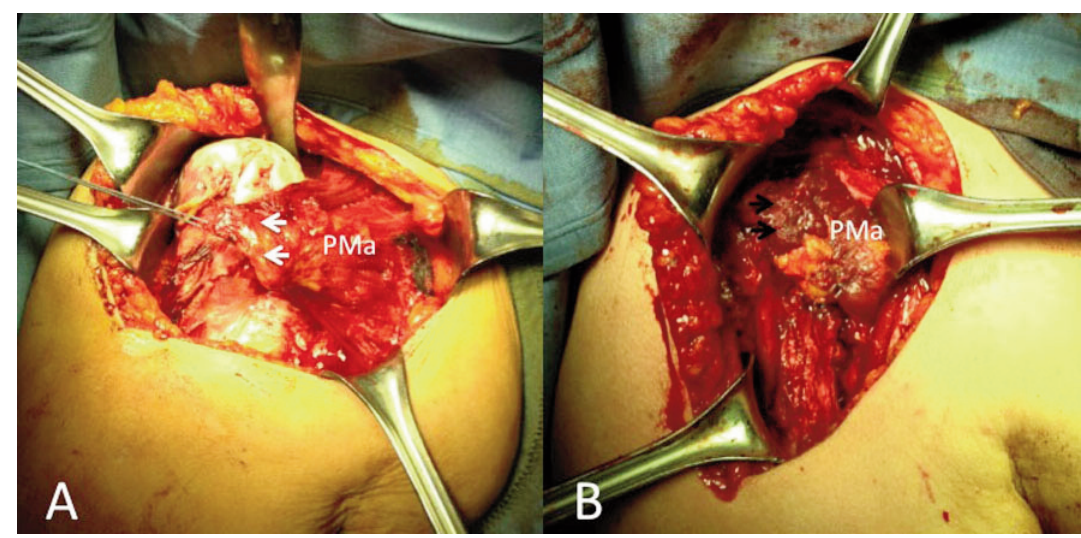

Figure 5 A, B. A) Pectoralis Major (PMa) released and pulled out (white arrows); B) PMa passed beneath the conjoined tendon and fixed to the lesser tuberosity of the humerus (black arrows). PMa: pectoralis major. 
perior $\mathrm{RCT}^{34,49,50,53}$. Jost et al. ${ }^{50}$ reported excellent mean relative Constant score (79\%) after PMa transfer. This study also showed that the ability to repair the supraspinatus improved the outcome compared with concomitant irreparable supraspinatus tears. Resch et al. ${ }^{34}$ were the first to report the technique of subcoracoid transfer of the PMa to the lesser tuberosity. In their group of 12 patients with a minimum follow-up of two years, the mean Constant score improved from 22.6 points preoperatively to 54.4 points postoperatively and most of the patients had marked improvement of pain. In addition, four of the patients with preoperative instability regained stability after surgery. Galatz et al. ${ }^{53}$ reported satisfactory results after subcoracoid transfer of the PMa tendon in 11 of 14 patients with a massive RCT with improvement in pain and function (ASES scores improved from 27.2 to 47.7 ). In a more recent study, Gavriilidis et al. ${ }^{49}$ described their experience of 15 patients treated after 37 months of follow-up. The authors reported an improvement in Constant score from 51.73 to 68.17 . Patients were also monitored by MRI to verify the integrity of the transferred tendon and an intact transferred tendon was described in $70 \%$ of patients ${ }^{49}$. On the contrary, different authors reported that patients with instability and anterior subluxation have the least predictable pain relief and worse functional outcomes ${ }^{50,53}$.

\section{Pectoralis minor transfer}

The PMi is a thin triangular muscle lying deep to the $\mathrm{PMa}$. It originates from the $3^{\text {rd }}, 4^{\text {th }}$ and $5^{\text {th }}$ ribs near the costal cartilages. Its fibers ascend laterally and converge in a flat tendon that attaches to the medial border and upper surface of the coracoid process of the scapula. The axillary vessels and brachial plexus lie posterior to the muscle. The PMi pulls the scapula anteriorly and inferiorly toward the ribs (abduction and depression respectively) leading to a dorsomedial movement of the inferior angle of the scapula. This movement is both helpful when retracting the elevated arm and as well as moving the arm posteriorly behind the back. Given a fixed scapula the PMi also elevates the $3^{\text {rd }}$ to $5^{\text {th }}$ ribs and expands the rib cage. For this reason, it can also serve as an accessory muscle during inspiration ${ }^{54}$.
PMi tendon as a graft to treat irreparable subscapularis tears was first used by Wirth and Rockwood ${ }^{55}$ who even tried to use the coracohumeral ligament, which is continuous with the coracoid insertion of the $\mathrm{PMi}^{56}$.

Inclusion criteria for a PMi transfer are as follow: irreparable RCT involving the upper two-thirds of the subscapularis tendon ${ }^{57}$ (Fig. 6 A); complete supraspinatus tear; and MRI evidence of fatty degeneration (grade III according to Fuchs et al. ${ }^{18}$ ) of the supraspinatus and upper subscapularis muscles ${ }^{58}$. All patients are operated under general anesthesia in a beach-chair position using the same standard deltopectoral approach described for PMa tendon transfer. After careful debridement of the subscapularis footprint and of the interval between the coracoid and the humeral head, the PMi tendon is detached from the coracoid with a bone fragment to foster the healing process and avoid muscle wasting (Fig. 6 B). Two stay sutures placed over the osteotomy are used to drag the PMi tendon, which usually reaches the lesser tuberosity without excessive tension, under the coracoid. The PMi is accurately released, taking care to identify and protect the musculocutaneous nerve, and then sutured in areas 2 and 3 as described by Arai et al. ${ }^{59}$ using 2 double-loaded suture anchors (Threvo FT; ConMed, Largo, FL, USA) (Fig. 7). The bellies of the inferior subscapularis and of the $\mathrm{PMi}$ can be joined horizontally with 2 free sutures and the biceps tenodesized or tenotomized. After the operation, the shoulder is immobilized in a sling for 6 weeks, active elbow flexion and extension are allowed with the arm at the side; at 6 weeks, the sling is removed and passive mobilizations in forward flexion and passive external rotation are permitted ${ }^{31,60}$. After 8 weeks all range-of-motion (ROM) restrictions were lifted, strengthening is initiated at 3 months ${ }^{31}$.

\section{Overview}

Tendon transfers are complex surgical procedures that require a long period of rehabilitation. They do not restore normal shoulder function and kinematics but can rather be considered as a salvage procedures. The functional outcomes and pain relief that can be achieved after surgery strictly depend on patient. The best candidate for a tendon transfer procedure is a young patient with irreparable RCT, no sign

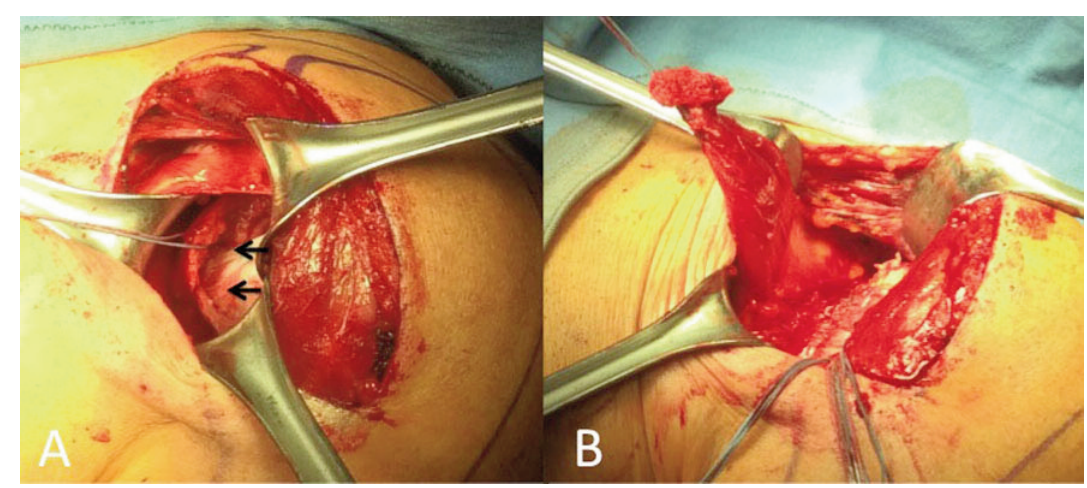

Figure 6 A, B. A) Subscapularis tear involving the upper two thirds of the tendon (black arrows); B) Pectoralis minor (PMi) tendon detached from the coracoid with a bone fragment to foster the healing process. 


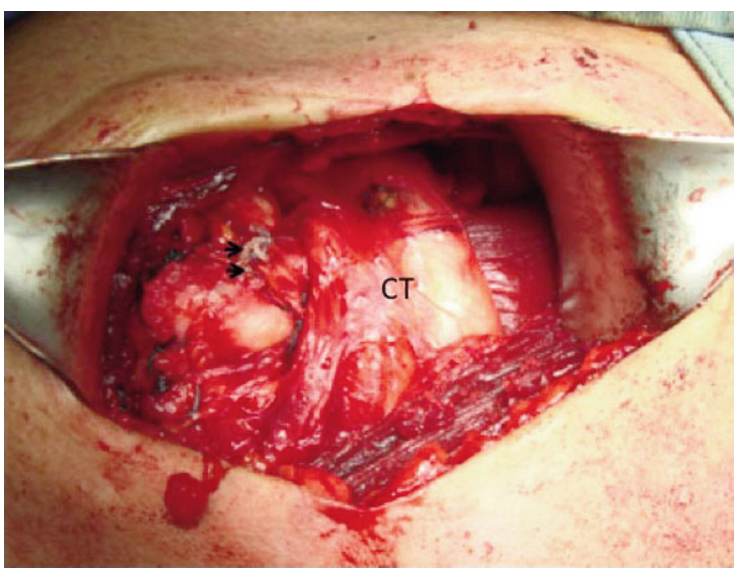

Figure 7. Pectoralis minor (PMi) fixed to the lesser tuberosity with 2 suture anchors (black arrows). The bellies of the inferior subscapularis and PMi joined horizontally with free sutures.CT: coracoid tendons.

of glenohumeral osteoarthritis and severe functional limitations due to muscle weakness. The choice of donor tendon depends on the location of the RCT. Currently, the two most common tendon transfer procedures involves LD for posterosuperior tears and PMa for anterosuperior tears.

\section{References}

1. Yamaguchi K, Ditsios K, Middleton WD, et al. The demographic and morphological features of rotator cuff disease. A comparison of asymptomatic and symptomatic shoulders. J Bone Joint Surg Am. 2006;88:1699-1704.

2. Zafra M, Carpintero P, Carrasco C. Latissimus dorsi transfer for the treatment of massive tears of the rotator cuff. Int Orthop. 2009;33(2):457-462.

3. Gigante A, Marinelli M, Chillemi C, Greco F. Fibrous cartilage in the rotator cuff: A pathogenetic mechanism of tendon tear? J Shoulder Elbow Surg. 2004;13(3):328-332.

4. Neer CS II. Anterior acromioplasty for the chronic impingement syndrome in the shoulder. J Bone Joint Surg Am. 1972;54:41-50.

5. Hashimoto T, Nobuhara K, Hamada T. Pathologic evidence of degeneration as aprimary cause of rotator cuff tear.Clin Orthop. 2003;415:111-120.

6. Lake SP, Miller KS, Elliott DM, Soslowsky LJ. Effect of fiber distribution and realignment on the nonlinear and in homogeneous mechanical properties of human supraspinatus tendon under longitudinal tensile loading. J Orthop Res. 2009;27:1596-1602.

7. Seitz AL, McClure PW, Finucane S, Boardman ND 3rd, Michener LA. Mechanisms of rotator cuff tendinopathy: intrinsic, extrinsic, or both? Clin Biomech. (Bristol, Avon) 2011;26(1):1-12.

8. Chillemi C, Petrozza V, Garro L. Rotator cuff re-tear or nonhealing: histopathological aspects and predictive factors. Knee Surg Sports Traumatol Arthrosc. 2011;19(9):1588-1596.

9. Harvie P, Ostlere SJ, Teh J, et al. Genetic influences in the aetiology of tears of the rotator cuff. Sibling risk of a full thickness tear. J Bone Joint Surg Br. 2004;86:696-700.

10. Omid R, Lee B. Tendon transfers for irreparable rotator cuff tears. J Am Acad Orthop Surg. 2013;21(8):492-501.

11. Yamaguchi K, Tetro AM, Blam O, Evanoff BA, Teefey SA, Middleton WD. Natural history of asymptomatic rotator cuff tears: a longitudinal analysis of asymptomatic tears detected sonographically. J Shoulder Elbow Surg. 2001;10(3):199-203.

12. DeOrio JK, Cofield RH. Results of a second attempt at surgical repair of a failed initial rotator cuff repair. J Bone Joint Surg Am. 1984;66:563-567.

13. Gerber C, Fuchs B, Hodler J. The results of repair of massive tears of the rotator cuff. J Bone Joint Surg Am. 2000;82:505515.

14. Ellman H. Rotator cuff disorders. In: Ellman H, Gartsman GM (eds). Arthroscopic shoulder surgery and related disorders. Lea and Febiger. Philadelphia. 1993;98-119.

15. Snyder SJ. Arthroscopic classification of rotator cuff lesions and surgical decision making. In: Snyder SJ (ed) Shoulder arthroscopy. Lippincott Williams \& Wilkins, Philadelphia. 2003;201-207.

16. Patte D. Classification of rotator cuff lesions. Clin Orthop Relat Res. 1990;254:81-86.

17. Goutallier D, Postel JM, Bernageau J, Lavau L, Voisin MC. Fatty muscle degeneration in cuff ruptures. Pre- and postoperative evaluation by CT scan. Clin Orthop Relat Res. 1994;(304):78-83.

18. Fuchs B, Weishaupt D, Zanetti M, Hodler J, Gerber C. Fatty degeneration of the muscles of the rotator cuff: assessment by computed tomography versus magnetic resonance imaging. J Shoulder Elbow Surg. 1999;8:599-605.

19. Rockwood CA Jr, Williams GR Jr, Burkhead WZ Jr. Débridement of degenerative irreparable lesions of the rotator cuff. $J$ Bone Joint Surg Am. 1995;77:857-866.

20. Dines DM, Moynihan DP, Dines J, McCann P. Irreparable rotator cuff tears: what to do and when to do it; the surgeon's dilemma. J Bone Joint Surg Am. 2006;88(10):2294-2302.

21. Goutallier D, Postel JM, Gleyze P, Leguilloux P, Van Driessche $S$. Influence of cuff muscle fatty degeneration on anatomic and functional outcomes after simple suture of full-thickness tears. J Shoulder Elbow Surg. 2003;12(6):550-554.

22. Lugo R, Kung P, Ma CB. Shoulder biomechanics. Eur J Radiol. 2008;68(1):16-24.

23. Parsons IM, Apreleva M, Fu FH, Woo SL. The effect of rotator cuff tears on reaction forces at the glenohumeral joint. J Orthop Res. 2002;20(3):439-446.

24. Bedi A, Dines J, Warren RF, Dines DM. Massive tears of the rotator cuff. J Bone Joint Surg Am. 2010;92(9):1894-1908.

25. Ahmad CS, Kleweno C, Jacir AM, Bell JE, Gardner TR, Levine WN, Bigliani LU. Biomechanical performance of rotator cuff repairs with humeral rotation: a new rotator cuff repair failure model. Am J Sports Med. 2008;36(5):888-892.

26. Keener JD, Wei AS, Kim HM, Steger-May K, Yamaguchi K. Proximal humeral migration in shoulders with symptomatic and asymptomatic rotator cuff tears. J Bone Joint Surg Am. 2009;91(6):1405-1413.

27. Merolla G, Paladini P, Saporito M, Porcellini G. Conservative management of rotator cuff tears: literature review and proposal for a prognostic. Prediction Score. MLTJ. 2011;1(1):1219.

28. Gartsman GM. Massive, irreparable tears of the rotator cuff. Results of operative debridement and subacromial decompression. J Bone Joint Surg Am. 1997;79(5):715-721 .

29. Wildemann B, Klatte F. Biological aspects of rotator cuff healing. MLTJ. 2012;1(4):161-168.

30. deCupis V, Chillemi C, Marinelli M. Grammont inverted prosthesis for the treatment of cuff tear arthropathy: a 6-year followup study. Orthopedics. 2008;31(5):447.

31. Paladini P, Campi F, Merolla G, Pellegrini A, Porcellini G. Pectoralis minor tendon transfer for irreparable anterosuperior cuff tears. J Shoulder Elbow Surg. 2013;22(6):e1-5.

32. Nelson GN, Namdari S, Galatz L, Keener JD. Pectoralis major tendon transfer for irreparable subscapularis tears. J Shoulder Elbow Surg. 2014;23(6):909-918. 
33. Namdari S, Voleti P, Baldwin K, Glaser D, Huffman GR. Latissimus dorsi tendon transfer for irreparable rotator cuff tears: a systematic review. J Bone Joint Surg Am. 2012;16;94(10):891898.

34. Resch H, Povacz P, Ritter E, Matschi W. Transfer of the pectoralis major muscle for the treatment of irreparable rupture of the subscapularis tendon. J Bone Joint Surg Am. 2000; 82:372-382.

35. Gerber C, Rahm SA, Catanzaro S, Farshad M, Moor BK. Latissimusdorsi tendon transfer for treatment of irreparable posterosuperior rotator cuff tears: long-term results at a minimum follow-up of ten years. J Bone Joint Surg Am. 2013;6;95:19201926.

36. Weening AA, Willems WJ. Latissimusdorsi transfer for treatment of irreparable rotator cuff tears. Int Orthop. 2010; 34:1239-1244.

37. Gerber C, Vinh TS, Hertel R, Hess CW. Latissimus dorsi transfer for the treatment of massive tears of the rotator cuff: A preliminary report. Clin Orthop Relat Res. 1988;232:51-61.

38. Gerber C. Latissimus dorsi transfer for the treatment of irreparable tears of the rotator cuff. Clin Orthop Relat Res. 1992;275:152-160.

39. lannotti JP, Hennigan S, Herzog R, et al. Latissimus dorsi tendon transfer for irreparable posterosuperior rotator cuff tears. Factors affecting outcome. J Bone Joint Surg Am. 2006;88: 342-348.

40. Irlenbusch U, Bernsdorf M, Born S, Gansen HK, Lorenz U. Electromyographic analysis of muscle function after latissimus dorsi tendon transfer. J Shoulder Elbow Surg. 2008; 17:492-499

41. Miniaci A, MacLeod M. Transfer of the latissimus dorsi muscle after failed repair of a massive tear of the rotator cuff. A two to five-year review. J Bone Joint Surg Am. 1999;81:1120-1127.

42. Warner JJ, Parsons IM 4th. Latissimus dorsi tendon transfer: a comparative analysis of primary and salvage reconstruction of massive, irreparable rotator cuff tears. J Shoulder Elbow Surg. 2001;10:514-521.

43. L'Episcopo JB. Tendon transplantation in obstetrical paralysis. Am J Surg. 1934;25:122-125.

44. Habermeyer P, Magosch P, Lichtenberg S. The modified L'Episcopo procedure to reconstruct masive rotator cuff tearsA prospective study. AAOS Congress 2002.

45. Beauchamp M, Beaton DE, Barnhill TA, Mackay M, Richards RR. Functional outcome after the L'Episcopo procedure. J Shoulder Elbow Surg. 1988;7:90-96.

46. Merolla G, Paladini P, Campi F, Porcellini G. Pectoralis major tendon rupture. Surgical procedures review. MLTJ. 2012;2:96103.
47. Gerhardt C, Lehmann L, Lichtenberg S, Magosch P, Habermeyer P. Modified L'Episcopo tendon transfers for irreparable rotator cuff tears: 5-year follow-up. Clin Orthop Relat Res. 2010;468:1572-1577.

48. Celli L, Rovesta C, Marongiu MC, Manzieri S. Transplantation of teres major muscle for infraspinatus muscle in irreparable rotator cuff tears. J Shoulder Elbow Surg. 1998;7:485-490.

49. Gavriilidis I, Kircher J, Magosch P, Lichtenberg S, Habermeyer P. Pectoralis major transfer for the treatment of irreparable anterosuperior rotator cuff tears. Int Orthop. 2010;34:689-694.

50. Jost B, Puskas GJ, Lustenberger A, Gerber C. Outcome of pectoralis major transfer for the treatment of irreparable subscapularis tears. J Bone Joint Surg Am. 2003;85:1944-1951.

51. Elhassan B, Ozbaydar M, Massimini D, Diller D, Higgins L, Warner JJP. Transfer of pectoralis major for the treatment of irreparable tears of subscapularis: does it work? J Bone Joint Surg Br. 2008;90:1059-1065.

52. Jennings GJ, Keereweer S, Buijze GA, De Beer J, DuToit D. Transfer of segmentally split pectoralis major for the treatment of irreparable rupture of the subscapularis tendon. J Shoulder Elbow Surg. 2007;16: 837-842.

53. Galatz LM, Connor PM, Calfee RP, Hsu JC, Yamaguchi K. Pectoralis major transfer for anterior-superior subluxation in massive rotator cuff insufficiency. J Shoulder Elbow Surg. 2003;12:1-5

54. Bhatia DN, de Beer JF, van Rooyen KS, Lam F, du Toit DF. The "bench-presser's shoulder": an overuse insertiona tendinopathy of the pectoralis minor muscle. $\mathrm{Br} \mathrm{J}$ Sports Med. 2007;41(8):e11.

55. Wirth MA, Rockwood CA Jr. Operative treatment of irreparable rupture of the subscapularis. J Bone Joint Surg Am. 1997;79:722-731.

56. Homsi C, Rodrigues MB, Silva JJ, Stump X, Morvan G. Anomalous insertion of the pectoralis minor muscle: ultrasound findings. J Radiol. 2003;84:1007-1011.

57. Lafosse L, Jost B, Reiland Y, Audebert S, Toussaint B, Gobezie R. Structural integrity and clinical outcomes after arthroscopic repair of isolated subscapularis tears. J Bone Joint Surg Am. 2007;89:1184-1193.

58. Kang JR, Gupta R. Mechanisms of fatty degeneration in massive rotator cuff tears. J Shoulder Elbow Surg. 2012;21:175180.

59. Arai R, Sugaya H, Mochizuki T, Nimura A, Moriishi J, Akita K. Subscapularis tendon tear: an anatomic and clinical investigation. Arthroscopy. 2008;24:997-1004.

60. Padulo J, Oliva F, Frizziero A, Maffulli N. Muscles, Ligaments and Tendons Journal. Basic principles and recommendations in clinical and field science research. MLTJ. 2013;4:250-252. 